\title{
Promoting smoking cessation during hospitalization for coronary artery disease
}

\author{
Robert D Reid PhD MBA, Andrew L Pipe CM MD, Bonnie Quinlan BSc RN
}

\begin{abstract}
RD Reid, AL Pipe, B Quinlan. Promoting smoking cessation during hospitalization for coronary artery disease. Can J Cardiol 2006;22(9):775-780.
\end{abstract}

BACKGROUND: Quitting smoking is the most effective intervention to reduce mortality in patients with coronary artery disease who smoke. Guidelines for the treatment of tobacco dependency recommend that health care institutions develop plans to support the consistent and effective identification and treatment of tobacco users. The University of Ottawa Heart Institute (Ottawa, Ontario) has implemented an institutional program to identify and treat all smokers admitted to the Institute.

OBJECTIVES: The objectives of the present paper are to describe core elements of this program and present data concerning its reach and effectiveness.

PROGRAM DESCRIPTION: The goal of the program is to increase the number of smokers who are abstinent from smoking six months after a coronary artery disease-related hospitalization. Core elements of the program include: documentation of smoking status at hospital admission; inclusion of cessation intervention on patient care maps; individualized, bedside counselling by a nurse counsellor; the appropriate and timely use of nicotine replacement therapy; automated telephone follow-up; referral to outpatient cessation resources; and training of medical residents and nursing staff. Program reach and effectiveness were measured over a one-year period.

RESULTS: Between April 2003 and March 2004, almost 1300 smokers were identified at admission, and $91 \%$ received intervention to help them quit smoking. At six-month follow-up, 44\% were smoke-free. CONCLUSIONS: Hospitalization for coronary artery disease provides an important opportunity to intervene with smokers when their motivation to quit is high. An institutional approach reinforces the importance of smoking cessation in this patient population and increases the rate of smoking cessation. Posthospitalization quit rates should be a benchmark of cardiac program performance.

Key Words: Coronary disease; Health care delivery; Prevention; Smoking

\section{La promotion de l'abandon du tabac pendant une hospitalisation secondaire à une coronaropathie}

HISTORIQUE : L'abandon du tabac est l'intervention la plus efficace
pour réduire la mortalité chez les patients fumeurs atteints d'une
coronaropathie. D'après les lignes directrices pour le traitement de la
dépendance au tabac, les établissements de santé doivent élaborer des
plans pour soutenir le dépistage et le traitement efficace et cohérent des
fumeurs. L'Institut de cardiologie de l'Université d'Ottawa a implanté un
programme pour repérer et traiter tous les fumeurs hospitalisés à l'Institut.
OBJECTIFS : Le présent article vise à décrire les principaux éléments de
ce programme et à présenter des données reliées à sa portée et à son
efficacité. DESCRIPTION DU PROGRAMME : Le programme vise à accroître le nombre de fumeurs qui s'abstiennent toujours de fumer six mois après une hospitalisation secondaire à une coronaropathie. Les principaux éléments du programme sont la documentation de l'état de fumeur au moment de l'hospitalisation, l'inclusion d'interventions d'abandon du tabac dans le plan de soins standard des patients, des conseils personnalisés au chevet du patient par une infirmière-conseil, le recours rapide et pertinent à une thérapie de remplacement de la nicotine, le suivi téléphonique automatisé, l'aiguillage vers des ressources externes d'abandon du tabac et la formation des résidents en médecine et du personnel infirmier. La portée et l'efficacité du programme ont été mesurées sur une période d'un an.

RÉSULTATS : Entre avril 2003 et mars 2004, plus de 1300 fumeurs ont été dépistés à l'hospitalisation, et $91 \%$ ont reçu une intervention pour les aider à cesser de fumer. Au suivi de six mois, $44 \%$ ne fumaient toujours pas.

CONCLUSIONS : L'hospitalisation secondaire à une coronaropathie constitue une excellente occasion pour intervenir auprès des fumeurs lorsque leur motivation à cesser de fumer est élevée. Une démarche en établissement renforce l'importance de l'abandon du tabac au sein de cette population de patients et accroît le taux d'abandon du tabac. Le taux d'abandon après l'hospitalisation devrait constituer un point de référence du rendement des programmes cardiaques.

CAD who smoke. Quitting smoking is as important as other secondary treatments, such as statins for lowering cholesterol $(29 \%$ reduction), acetylsalicylic acid (15\%), beta-blockers (23\%) and angiotensin-converting enzyme inhibitors (23\%) (2).

In Canada, more than 230,000 CAD-related hospitalizations were projected in 2005 (3). Evidence suggests that 20\% of those hospitalized with CAD (approximately 46,000) were smokers (4). Guidelines for the treatment of tobacco dependency recommend that health care institutions implement intervention or treatment to reduce mortality in patients with

Prevention and Rehabilitation Centre, University of Ottawa Heart Institute, Ottawa, Ontario

Correspondence: Dr Robert D Reid, Prevention and Rehabilitation Centre, University of Ottawa Heart Institute, 40 Ruskin Street, Ottawa,

Ontario K1Y 4W7. Telephone 613-761-5058, fax 613-761-5336, e-mail breid@ottawaheart.ca

Received for publication September 9, 2005. Accepted December 13, 2005 
supportive systems, policies and environmental prompts to encourage and support consistent and effective identification and treatment of tobacco users $(5,6)$. Despite guidelines, clear links between smoking and CAD, and the presence of effective cessation interventions (7), few cardiac programs in Canada have such programs in place.

The University of Ottawa Heart Institute (UOHI) is a tertiary care cardiac institution, that serves 1.3 million inhabitants of the Champlain region of Ontario. The UOHI has implemented an institutional program to identify and treat tobacco users. The objectives of the present paper are to describe the core elements of this program and to present data concerning the program's reach and effectiveness.

\section{PROGRAM DESCRIPTION}

The program logic model (Table 1) shows how program inputs, activities, outputs and outcomes are linked to achieve desired results over time. The goal of this program is to increase the number of smokers who are abstinent from smoking six months after a CAD-related hospitalization.

\section{Program inputs}

'Inputs' are the resources (processes and policies, people, budget and materials) that go into the institutional effort to identify and treat tobacco users. Processes and policies that have been developed to support the program include the adoption of smoking status following hospitalization as a benchmark for hospital performance; the inclusion of smoking status on the patient chart; the addition of smoking cessation counselling on patient care maps; the preparation of standard orders for pharmacotherapies to support cessation; and the stocking of these pharmacotherapies in the hospital pharmacy. Our program is delivered by a 1.0 full-time equivalent specialist nurse counsellor and a 1.0 full-time equivalent administrative assistant. Medical support is provided by the director of the Division of Prevention and Rehabilitation and financial support is provided by UOHI, with a budget of $\$ 144,000$ per year. Materials used in the program include a series of patient self-help materials (developed by the Canadian Cancer Society) $(8,9)$, pharmacotherapies, an interactive voice response (IVR) follow-up system and a program evaluation database.

\section{Program activities}

'Program activities' include all the services that occur or are provided as part of the program.

At hospital admission, smoking status is identified through the patient's medical and/or nursing history and is documented in the patient record. Smoking status is determined using a standard question: "Have you used any form of tobacco in the past six months?" In a nonjudgemental, unambiguous and personalized manner, the attending physician or nurse advises all current smokers to quit. All hospitalized smokers are referred to the specialist nurse counsellor as part of the standard orders and as described in the patient care maps. The nurse counsellor provides minimal or intensive counselling in accordance with the nursing Best Practice Guidelines (10), based on the patient's readiness to quit smoking.

If the patient is not ready to quit, the discussion focuses on the pros and cons of continued smoking versus cessation, considering the reason for hospitalization. All smoking patients are encouraged to use nicotine replacement therapy (NRT) during hospitalization to reduce symptoms of nicotine withdrawal. They are provided with a self-help booklet (8) and a list of contacts for smoking cessation assistance (eg, UOHI outpatient smoking cessation program, provincial Quitline, public health cessation groups) for future reference.

For patients who are ready to quit, a quit plan is developed using behavioural techniques, the need for pharmacotherapy is assessed and patients are provided with a self-help booklet (9). The counselling session includes specific, brief discussions about issues central to successful cessation, such as approaches to weight gain, behavioural components of smoking, stress management, and family or spousal smoking behaviours. Additional information regarding these subjects, present in the self-help booklet, is identified for the patients. NRT is recommended for most smokers and a standard order for NRT is authorized by the attending cardiologist or surgeon. A patient information handout and appropriate counselling regarding the proper use of NRT is provided. Patients were asked if any other people in their homes smoke, and these individuals are also offered support. Typically, this involves a family session in which pharmacotherapy and behavioural strategies are discussed and specific assistance is offered.

NRT, mostly in the form of nicotine patches, is provided to patients during the hospitalization period. The initial dosage is determined by the average number of cigarettes smoked per day before hospital admission. Patients smoking 10 or fewer cigarettes per day are prescribed $7 \mathrm{mg} / 24 \mathrm{~h}$, those smoking 11 to 20 cigarettes per day are prescribed $14 \mathrm{mg} / 24 \mathrm{~h}$, and those smoking 20 or more cigarettes per day are prescribed $21 \mathrm{mg} / 24 \mathrm{~h}$. Based on the patient's response to therapy, doses may be titrated during hospitalization. A copy of the orders for NRT is provided to the attending cardiologist or surgeon. At discharge, patients are provided with guidelines for a 10-week NRT program. Following discharge, it is the patient's responsibility to obtain the NRT at his or her own pharmacy. Recommendations to support smoking cessation are written in the discharge letter sent to the primary care physician.

Evidence strongly indicates that NRT doubles cessation rates (6). Cardiac specialists and primary care physicians have debated the use of NRT in patients with CAD, largely due to the concern that nicotine from the patch may increase heart rate, blood pressure and coronary vasoconstriction. A literature review has shown that nicotine delivered by NRT patches has similar or lesser effects than cigarette smoking with respect to increasing myocardial work or coronary vascular resistance $(7,8)$. The risks associated with NRT for smokers with CAD are considered small and are outweighed by the benefits of quitting smoking (7). Considerable evidence supports NRT safety for patients with stable CAD (9-11), and a recent retrospective review (12) indicated that the use of NRT in acute coronary syndrome patients had no impact on seven-day or 30-day mortality. Nicotine delivered via the patch enters the venous system at levels markedly lower than those produced in the arterial system by the inhalation of tobacco smoke. By delivering a level of nicotine close to an individual's idiosyncratic nicotine 'threshold,' the urge to smoke can be blunted or eliminated. Smokers using NRT receive much lower levels of nicotine than they would if they were to leave the hospital unit to smoke. They do not receive any of the many other compounds present in tobacco smoke (including carbon monoxide).

Patients are contacted three, 14 and 30 days following hospital discharge using an IVR system (see Appendix). This system 
TABLE 1

Logic model for an institutional approach to smoking cessation at the University of Ottawa Heart Institute (UOHI)

\begin{tabular}{|c|c|c|c|c|}
\hline Resources/inputs & Processes/activities & Outputs & Outcomes & Impacts \\
\hline $\begin{array}{l}\text { - Policies and processes } \\
\text { - Smoking status as } \\
\text { a performance benchmark } \\
\text { - Smoking status on } \\
\text { patient chart } \\
\text { - Cessation counselling } \\
\text { on care maps } \\
\text { - Standard orders for } \\
\text { pharmacotherapy } \\
\text { - Staffing } \\
\text { - Nurse-specialist } \\
\text { - Administrative support } \\
\text { - Medical director } \\
\text { - Research associate } \\
\text { - Financial resources } \\
\text { - Materials } \\
\text { - Self-help booklets } \\
\text { - Pharmacotherapy } \\
\text { - IVR follow-up system } \\
\text { - Program evaluation } \\
\text { database }\end{array}$ & $\begin{array}{l}\text { - Documenting smoking status } \\
\text { of all patients admitted to } \\
\text { the UOHI } \\
\text { - Advising all smoking patients } \\
\text { to quit } \\
\text { - Providing counselling to all } \\
\text { smokers during their } \\
\text { hospitalization } \\
\text { - Providing self-help materials } \\
\text { to all smokers } \\
\text { - Providing pharmacotherapy } \\
\text { to those patients experiencing } \\
\text { significant withdrawal symptoms } \\
\text { - Contacting patients after discharge } \\
\text { to assess smoking status and } \\
\text { need for additional support } \\
\text { - Providing outpatient counselling } \\
\text { to those experiencing difficulty } \\
\text { postdischarge or relapsers } \\
\text { - Assessing smoking status } \\
\text { six months postdischarge } \\
\text { - Training physicians and nursing } \\
\text { assistance to patients who smoke }\end{array}$ & $\begin{array}{l}\text { - Number of smokers } \\
\text { identified and } \\
\text { documented } \\
\text { - Number of smokers } \\
\text { who receive counselling } \\
\text { to help them quit } \\
\text { - Number of patients } \\
\text { who receive } \\
\text { pharmacotherapy } \\
\text { - Number of patients } \\
\text { contacted by the IVR } \\
\text { system } \\
\text { - Number of patients } \\
\text { receiving additional } \\
\text { outpatient support } \\
\text { - Number of patients } \\
\text { contacted for } \\
\text { outcome assessment } \\
\text { - Number of physicians } \\
\text { and nurses trained }\end{array}$ & $\begin{array}{l}\text { - Increased motivation } \\
\text { to quit smoking } \\
\text { - Increased confidence } \\
\text { to quit smoking } \\
\text { - More attempts to quit } \\
\text { smoking } \\
\text { - Fewer withdrawal } \\
\text { symptoms } \\
\text { - Greater likelihood } \\
\text { of quitting smoking } \\
\text { - Greater abstinence } \\
\text { from smoking at follow-up } \\
\text { - Physicians and nurses } \\
\text { have increased confidence } \\
\text { in their ability to help } \\
\text { smokers }\end{array}$ & $\begin{array}{l}\text { - All-cause and cardiac } \\
\text { morbidity is reduced } \\
\text { - All-cause and cardiac } \\
\text { mortality is reduced } \\
\text { - Hospital admissions } \\
\text { are reduced }\end{array}$ \\
\hline
\end{tabular}

IVR Interactive voice response

poses a series of questions concerning the patient's current smoking status, confidence in staying smoke-free until the next planned call, and the use of pharmacotherapy, self-help materials and other forms of cessation support. If patients indicate that they have resumed smoking or that their confidence in remaining smoke-free is low, then they are contacted by the nurse counsellor. Assistance is then provided based on personal preference: a patient may choose to receive ongoing telephone counselling from the nurse; be referred to the UOHI outpatient smoking cessation clinic; be referred to the provincial Quitline; or be directed to cessation programs in a local community.

Outcomes are assessed six months after hospital discharge for program and process evaluation purposes only. Patients are contacted by telephone and a seven-day point-prevalent abstinence ("not even a puff") or a continuous abstinence ("no smoking since hospital discharge") is determined. The use of cessation supports is documented and satisfaction with the nurse counselling process is evaluated.

The nurse counsellor received training in all aspects of nicotine dependency and smoking cessation from experienced medical staff members and in the development and delivery of national or provincial programs designed to address tobacco dependency (RR, AP and others). In addition, the nurse counsellor participated in a number of professional development activities on smoking cessation. The Best Nursing Practice Guidelines (10) have been developed and reviewed, in part, by members of the UOHI medical and nursing staff. A 1 h training session in the management of tobacco dependency is provided to all new medical residents in cardiology and cardiac surgery, as well as to all nurses new to UOHI. Ongoing 'in-service' training is provided to meet the continuing education needs of nurses and other health professionals.
Program outputs

'Program outputs' are defined as participation in, and reach of, the program activities. These contacts can be counted directly and form the basis of process evaluation of the program. Key patient-related outputs include the number of smokers that were identified and documented at admission; received in-hospital counselling from the nurse counsellor; received pharmacotherapy during hospitalization; received additional support from UOHI posthospitalization (either by telephone counselling, participation in the outpatient cessation program or in other relevant cessation activities); were contacted by the IVR system posthospitalization; were referred to other outpatient resources; and were contacted for outcome assessment. An equally important output is the number of medical and nursing staff receiving training in the management of tobacco dependency throughout a given period.

\section{Program outcomes}

'Program outcomes' are the specific changes intended as the result of the institutional program to identify and treat tobacco users. Short-term outcomes at the patient level include increased motivation to quit smoking, increased confidence in the ability to remain smoke-free after hospitalization, a reduction in 'behavioural issues' and other manifestations of nicotine withdrawal during hospitalization, fewer withdrawal symptoms during the quitting process and greater use of community cessation support services. Medium-term outcomes include abstinence from smoking six months after hospitalization or a reduction in the number of cigarettes smoked compared with prehospitalization levels, and a reduction in the number of rehospitalizations for CAD in the year following the index admission. Longer-term impacts include abstinence from 
smoking one or more years after hospitalization and reduced long-term morbidity and mortality.

\section{Prevalence of smoking}

\section{RESULTS}

Between April 2003 and March 2004, a total of 6381 patients were admitted to the UOHI: 3223 for inpatient cardiology (acute coronary syndrome, percutaneous coronary intervention), 1380 for inpatient surgery, and 1778 for diagnostic catheterization procedures. The overall prevalence of smoking was $20.0 \%$ (1276 of 6381$)$ and the smoking rate was stable across patient subgroups.

\section{Program outputs}

Of the 1276 smokers identified at admission, 1164 (91\%) were seen by the nurse counsellor and were provided minimal $(70 \%)$ or intensive $(30 \%)$ counselling. It was not possible to provide assistance to a small number smokers who were admitted only briefly (a significant proportion of whom were admitted following a percutaneous coronary intervention), who refused any offer of assistance, or in whom smoking status may have been misidentified. The average age of those receiving counselling was 56 years. These patients were predominantly male (78\%) and $90 \%$ were ready to quit smoking at the time of the counselling; NRT was prescribed in-hospital to $33 \%$ of patients. The IVR system was able to establish contact posthospitalization with $74 \%$ of patients, and $50 \%, 54 \%$, and $54 \%$ reported not smoking three, 14 , and 30 days posthospitalization, respectively. Fifty-three per cent of patients received additional smoking intervention from UOHI after discharge. Of these patients, $90 \%$ opted to receive telephone support from the nurse counsellor and $10 \%$ participated in the outpatient smoking cessation program. Eighty-nine per cent of patients were available for outcome assessment six months after hospitalization. For the purposes of outcome analysis, patients who could not be contacted were considered smokers.

During the year, 30 medical residents and 120 nurses and other allied health professionals received training in techniques for the treatment of tobacco dependency.

\section{Program outcomes}

Six months after hospitalization, $44 \%$ of patients reported not smoking in the seven days preceding the follow-up telephone call (point-prevalence abstinence) and 35\% reported no smoking since hospitalization (continuous abstinence).

\section{DISCUSSION}

Quitting smoking is a very important goal for smokers with CAD. We have described an institutional approach to assist tobacco users admitted to the UOHI. Our data indicate that such an approach can reach a large number of smokers when their motivation to quit smoking is high; however, there is still much room for improvement. Even with intervention, many patients with CAD continue or resume smoking after hospitalization for important events such as myocardial infarction, angioplasty and coronary bypass surgery. Our quit rate, measured six months after hospitalization, was $44 \%$. This rate is somewhat lower than that reported in clinical trials of smoking interventions in cardiac patients, which ranged from $50 \%$ to $60 \%$ (7). A possible explanation for this is that we were much less selective within our patient pool because we did not use the rigid eligibility criteria common to clinical trials. As a result, our approach had a much higher reach $-90 \%$ of smokers admitted to UOHI - compared with the $30 \%$ to $50 \%$ reach reported in most clinical trials of smoking intervention in this population (11). Our experience likely typifies the 'real world' of program implementation. Another explanation for our lower quit rate is that the overall prevalence of smoking in the population is declining compared with that of earlier studies, leaving only the most dependent, and thus more difficult-to-treat, smokers. This is consistent with evidence suggesting that the efficacy of behavioral and pharmacological smoking intervention has declined over time because of the more deeply embedded dependency of today's smokers $(12,13)$. Our $44 \%$ cessation rate at six months nonetheless represents a $15 \%$ absolute increase over our previous institutional experience. In our view, this is the most important measure of success of our system and its processes. Actual rates of successful cessation are best evaluated with biochemical validation at 12 months postintervention; such evaluation of our patients will be performed at that time.

Several strengths of our institutional program have been recognized: institutional leaders have made a strong commitment to the goal of reducing smoking among hospitalized patients, and smoking status following hospitalization has been adopted as a quality indicator. The presence of a dedicated smoking cessation nurse counsellor has vastly improved the quality and consistency of intervention offered to tobaccodependent patients. The nurse counsellor has also been instrumental in devising standard orders, revising care maps, training nursing and medical staff, developing environmental prompts to support cessation messages, and ensuring that self-help resources and pharmacotherapies are readily available to patients. We have found the IVR system to be an efficient tool for conducting patient follow-up after discharge and for identifying those patients in need of additional assistance. Patients frequently mention that the program has helped reinforce the importance of quitting smoking to prevent a recurrence of CAD. It has been our experience that the appropriate and timely use of NRT has more effectively addressed in-hospital nicotine withdrawal with a reduced incidence of 'behavioural problems' and a lessening reliance on anxiolytics and other measures to deal with these often troubling and underappreciated symptoms.

Program limitations must also be identified. The evidence base for the use of NRT in actue coronary syndrome patients is modest. We have been carefully documenting our experience, and no adverse events were recorded. Some clinicians will continue to be wary of NRT use in the acute setting despite the clear recognition that it releases lower levels of nicotine at a steady pace into the venous system, and provides none of the many other compounds contained in cigarette smoke. Smokers using NRT are therefore in a less hazardous situation than those who leave the hospital to smoke at any time of day or night. An ongoing commitment to the training of medical residents and nursing staff is required due to turnover in these areas. Clearly, some smokers require intensive support over an extended period of time to achieve abstinence from smoking. While we are able to provide some of this support through telephone counselling and our outpatient smoking cessation clinic, stronger linkages with community-based cessation programs and services are required. In Ontario, the Ministry of Health Promotion has launched a new initiative (14) to expand 
cessation supports and community programs that should assist in addressing this concern.

We envision our institutional program evolving in at least three ways. First, the program will continue to incorporate new evidence-based innovations in intervention. For example, new pharmacotherapies for cessation are currently in development, and we will work to establish the safety and efficacy of these therapies in cardiac patients. Second, we are developing a network of hospital-based smoking cessation programs in the Champlain region of Ontario. Hospitals in the network will use a common approach to identify, document and provide intervention to tobacco users. The opportunity to share data and experiences will exponentially increase the speed with which the effects of institutional approaches can be evaluated and will transform institutional practice region-wide. Third, we will explore the potential of harm reduction approaches (15) using conventional (NRT) or anticipated pharmacotherapies as a means to assist cardiac smokers who are unable to quit despite concerted efforts.

Knowledge translation experts suggest that changes in the practice setting are instrumental to transforming professional behaviour (16). In turn, the practice setting is an environment with a variety of social, organizational and policy influences. The institutional program for assisting tobacco users described in the present study is an example of how these influences have been harnessed to reduce a significant care gap in those with CAD. Professional practice in our institution has been transformed. Our experiences may prove informative to other institutions considering such a program. It is inconceivable that health care institutions and professionals would not measure blood pressure at the time of any admission and intervene appropriately with the hypertensive patients so identified. Given that smoking is the leading preventable cause of death and disease in Canada, it is surprising that most institutions (and until recently, this included UOHI) do not have simple measures in place to identify smokers and offer them effective measures in support of cessation. The development and application of simple, inexpensive systems to accomplish this could have a profound effect on community health.

ACKNOWLEDGEMENTS: The authors thank Shauna Stewart for her assistance with patient follow-up and data collection. The authors also acknowledge the ongoing support of the Ontario Ministry of Health Promotion.

FUNDING: Robert D Reid is supported by a New Investigator Award from the Heart and Stroke Foundation of Canada.

\section{APPENDIX \\ Interactive voice response: Questions and responses}

1a) "Are you [patient's name]?"

If "yes" to 1a:

2a) "Have you smoked any cigarettes, even a puff, since you left the hospital?"

If "no" to $2 \mathrm{a}$ :

3a) "On a scale of $1-10$, with 10 being the most confident, how confident are you that you will remain a non-smoker?" If self-efficacy 7 or $>$ :

4. "What quit method are you using?

a. Nicoting patch, gum or inhaler;

b. Zyban (Biovail Pharmaceuticals, Canada);

c. Self-help books;

d. Counselling, such as telephone quit lines or web sites;

e. Any other method."

5. "Thank you and congratulations. Remaining smoke-free is the most important thing you can do to positively affect your heart health! We will be calling again in 11 days. If you need any assistance, please feel free to call the Smoking Cessation Nurse Counsellor at 798-5555."

If self-efficacy <7:

3b) "Thank you. We know how difficult it can be to remain smoke-free. The Smoking Cessation Nurse Counsellor will be calling you within the next 48 hours to help you deal with any difficulties you may be experiencing. If you would like to speak with the Smoking Cessation Nurse Counsellor earlier, please call 798-5555."

If "no" to 1a:

1b) "Thank you. We would like to reach [patient's name]. We will try again we can be reached at ."

If "yes" to 2a:

2b) "How many cigarettes per day are you smoking?"

Continued on next page 


\section{APPENDIX - continued \\ Interactive voice response: Questions and responses}

2c) "Do you want to quit?"

If "no" to $2 \mathrm{c}$ :

2d) "We understand that you are not ready to quit right now. Things can change and should you need any information on how to quit or support during this process, please do not hesitate to call the Smoking Cessation Nurse Counsellor at 798-5555."

If "yes" to 2c:

2e) "Do you want to quit within the next week?"

If "yes" to $2 e:$

2f) "Great! Quitting smoking is the most important thing you can do to positively affect your heart health! Our Smoking Cessation Nurse Counsellor will be calling you within 48 hours to help you develop a plan. Please don't hesitate to call should you wish to speak with the Smoking Cessation Nurse Counsellor at any time. The number to call is 798-5555."

If "no" to $2 e$ :

$2 \mathrm{~g}$ ) "We understand you are not ready right now. Please do not increase the number of cigarettes you are now smoking. We will be calling again in 11 days to see how you are doing. Please don't hesitate to call the Smoking Cessation Nurse Counsellor at any time should you feel you need support or information at 798-5555."

\section{REFERENCES}

1. Ludvig J, Miner B, Eisenberg MJ. Smoking cessation in patients with coronary artery disease. Am Heart J 2005;149:565-72.

2. Critchley JA, Capewell S. Mortality risk reduction associated with smoking cessation in patients with coronary heart disease: A systematic review. JAMA 2003;290:86-97.

3. Heart and Stroke Foundation of Canada. The Growing Burden of Heart Disease and Stroke in Canada. Ottawa: Heart and Stroke Foundation of Canada, 2003.

4. Reid R, Pipe A, Higginson L, et al. Stepped care approach to smoking cessation in patients hospitalized for coronary artery disease. J Cardiopulm Rehabil 2003;23:176-82.

5. Fiore MC, Hatsukami DK, Baker TB. Effective tobacco dependence treatment. JAMA 2002;288:1768-71.

6. Pipe A. Smoking. Can J Cardiol 1999;15(Suppl G):77G-80G.

7. van Berkel TF, Boersma H, Roos-Hesselink JW, et al. Impact of smoking cessation and smoking interventions in patients with coronary heart disease. Eur Heart J 1999;20:1773-82.

8. Canadian Cancer Society. One Step at a Time for Smokers Who Don't Want to Quit. Toronto: Canadian Cancer Society, 1999.
9. Canadian Cancer Society. One Step at a Time for Smokers Who Want to Quit. Toronto: Canadian Cancer Society, 1999.

10. Registered Nurses Association of Ontario. Integrating Smoking Cessation into Daily Nursing Practice. Toronto: Registered Nurses Association of Ontario, 2003.

11. France EK, Glasgow RE, Marcus AC. Smoking cessation interventions among hospitalized patients: What have we learned? Prev Med 2001;32:376-88.

12. Irvin JE, Brandon TH. The increasing recalcitrance of smokers in clinical trials. Nicotine Tob Res 2000;2:79-84.

13. Irvin JE, Hendricks PS, Brandon TH. The increasing recalcitrance of smokers in clinical trials II: Pharmacotherapy trials. Nicotine Tob Res 2003;5:27-35.

14. Ontario Ministry of Health Promotion. <www.mhp.gov.on.ca/ english/default.asp> (Version current at June 26, 2006).

15. McNeill A. Harm reduction. BMJ 2004;328:885-7.

16. Tremblay GJ, Drouin D, Parker J, et al. The Canadian Cardiovascular Society and knowledge translation: Turning best evidence into best practice. Can J Cardiol 2004;20:1195-8. 